\title{
Epidemiological Approach to Understand Rheumatic Heart Valve Disease: Case of Thoracic Cardiovascular Clinic of Fann Hospital (Dakar)
}

\author{
Marie Parsine Sall ${ }^{*}$, Fatimata Mbaye ${ }^{1}$, Mbacké Sembéne$^{2}$, Amadou Gabriel Ciss ${ }^{3}$ \\ ${ }^{1}$ Département de Biologie Animale, Faculté des Sciences et Techniques, Université Cheikh Anta Diop, Dakar, Sénégal \\ ${ }^{2}$ Institut de Recherche Pour le Développement, Campus Bel-Air, Université Cheikh Anta Diop, Dakar, Sénégal \\ ${ }^{3}$ Faculté de Médecine, de Pharmacie et D’odontologie, Université Cheikh Anta Diop, Dakar, Sénégal \\ Email: ^Marieparsine.sall@ucad.edu.sn,mbacke.sembene@ird.fr2,cissgaby@yahoo.fr
}

How to cite this paper: Sall, M.P., Mbaye, F., Sembéne, M. and Ciss, A.G. (2020) Epidemiological Approach to Understand Rheumatic Heart Valve Disease: Case of Thoracic Cardiovascular Clinic of Fann Hospital (Dakar). World Journal of Cardiovascular Diseases, 10, 750-760.

https://doi.org/10.4236/wjcd.2020.1010071

Received: August 4, 2020

Accepted: October 27, 2020

Published: October 30, 2020

Copyright (c) 2020 by author(s) and Scientific Research Publishing Inc. This work is licensed under the Creative Commons Attribution-NonCommercial International License (CC BY-NC 4.0). http://creativecommons.org/licenses/by-nc/4.0/

\begin{abstract}
Objective: Rheumatic heart disease is the major cause of heart valve disease in developing countries. In Senegal, cardiac pathology is dominated by rheumatic pathology whose hospital prevalence was estimated at $0.15 \%$ [1]. Epidemiological data on rheumatic heart valve disease (RHVD) are unfortunately imprecise due to the lack of good quality data collection in a large number of countries, especially in sub-Saharan areas and in Central Asia. The objective of this epidemiological study is to collect data about rheumatic heart valve disease in our clinic which is the only surgical center of Senegal. Patients and Methods: Our study conducted between 2014 and 2017 involved a population of one hundred and eighty-three patients with complete medical records, all followed at the Thoracic and Cardiovascular Surgery Clinic at Fann Hospital for rheumatic valve disease. This population was the subject of an epidemiological survey based on a questionnaire covering clinical parameters as consanguinity, clinical signs, diagnosis and surgical intervention. Results: Our work is an epidemiological study involving one hundred and eighty-three (183) patients with various types of rheumatic valve disease, followed at the Thoracic and Cardiovascular Surgery Clinic at Fann Hospital, and who responded to a questionnaire about clinical aspects of this disease. Our results showed $5.46 \%$ of family cases, of which $2.18 \%$ came from consanguineous marriages. Mean age at onset of clinical signs was $14 \pm 9$ years with $14.20 \%$ before 6 years of age, $65.91 \%$ between 6 and 21 years and 19.89\% in adulthood. Average age of diagnosis was $21 \pm 11$ years with an average delay between diagnosis and intervention of 10 years \pm 14 . Mitral stricture
\end{abstract}


(22.5\%) was the most common diagnosis, followed by mitral disease (17.9\%) and mitral regurgitation (6.9\%). Surgical procedures involved $31.8 \%$ of mitral valve, $8.79 \%$ of aortic valve, $12.09 \%$ of mitral and aortic valves, $13.74 \%$ of mitral and tricuspid valves, $2.75 \%$ of 3 valves mitral, aortic and tricuspid. $27.49 \%$ of patients were awaiting surgery. Conclusion: It appears that a considerable effort should be made to prevent the pathology, to make population aware of the clinical signs and to improve the accessibility of patients to surgical procedure. These different actions would reduce the incidence and prevalence of the disease in Senegal.

\section{Keywords}

Rheumatic, Valves, Epidemiological, Diagnosis, Surgery

\section{Introduction}

Worldwide, there are 70 million cases of rheumatic heart disease (RHD) with 1.4 million deaths annually [2]. RHVD remains a real public health problem in developing countries and leads to 233,000 deaths per year. Although it has largely disappeared from developed countries, it continues to be a major cause of early death and morbidity in poor and developing countries. The global prevalence of RHVD is estimated at 15.6 million with 282,000 new cases each year. Sub-Saharan Africa has the highest prevalence with 30 per 1000 among students, which is due to the fact that this region is considered to be the global hotspot for rheumatic fever [3] [4]. In Senegal, cardiac pathology is dominated by RHVD and the first open heart surgery was performed in 1996 [5].

The objective of this epidemiological study was to conduct an in-depth review of patients followed and operated at the Dakar Thoracic and Cardiovascular Surgery Clinic (TCVC) in order to collect data about the proportion of people affected by RHVD, the most frequent types of RHVD, factors influencing the occurrence of this disease, the degree of therapeutic and surgical management of patients.

\section{Patients and Methods}

A population of TCVC patients which diagnosis was made using Jones criteria for ARF, cardiac ultrasound, echo-Doppler and ASLO (detection of antistreptolysin O) test for RHVD were the subject of an epidemiological study between January 2014 and December 2017 (Table 1). These patients responded to a questionnaire which covered clinical parameters as consanguinity, clinical signs, diagnosis and surgical intervention. In the results, only those patients who answered the question on the study endpoint were counted in the study population. Characteristics of the study population are on the Table 1.

The data collected during this survey were processed by EPI Info software version 7.2.2.2 and Microsoft Excel 2007. Ages at the onset of the first clinical manifestations, ages of patients at the time of diagnosis and surgery were 
Table 1. Characteristics of study population.

\begin{tabular}{cc}
\hline Value & Number \\
\hline Population size & 183 \\
Female & 136 \\
Male & 47 \\
Average age of patients & $33 \pm 11$ ans \\
Number of operated patients & 133 \\
\hline
\end{tabular}

grouped into age groups using Sturge's rule [6] according to which the class number: $\mathrm{NC}=1+3.3$ logn, the class interval: $I C=X_{\max }-X_{\min } / N C\left(X_{\max }\right.$ corresponding to the maximum age and $X_{\min }$ to the lowest age). Likewise, times between age of first symptoms and age of diagnosis as well as times between age of diagnosis and age of surgery were calculated and grouped into age groups. This allowed us for each quantitative variable to output frequencies, means and standard deviation and thus, to make statistical analyzes.

\section{Results}

Our epidemiological survey was carried out on a global population of 183 patients; one hundred and thirty-six of them were women, and forty-seven men, for a sex ratio of 0.34 .

\subsection{Family Cases}

Our results reported 10 family cases (5.46\%) of which nearly half of them either (40\%) come from consanguineous parents (Table 2).

\subsection{Age of Onset of First Clinical Signs}

Patients would perceive clinical signs relatively early, the average age for the first clinical signs being equal to $14 \pm 9$ years. In most patients, signs appeared before the age of 16 (14.20\% between $1-6$ years, 31.82\% between 6 and 11 years, $26.14 \%$ between 11 and 16 years).

\subsection{Frequency of Symptoms According to Age Groups}

Orthopnea is the clinical sign most perceived by patients $(76.51 \%)$. The four other most perceived signs are $49.18 \%$ recurrent angina, $32.79 \%$ rheumatic fever, anasarca (24.04\%) and finally chest pain (14.75\%) (Table 3).

\subsection{Patients' Age at Diagnostic}

The vast majority of diagnoses are carried out between 8 and 29 years with $22.47 \%$ in age group $8-15,23.60 \%$ in age group $15-22$ and $17.42 \%$ in age group 22 - 29. Average age of diagnosis was $21 \pm 11$ years (Figure 1 ).

\subsection{Delays between Year of Symptoms and Date of Diagnosis}

The most frequent delay between appearance of symptoms and diagnosis is 
Table 2. Proportion of family cases.

\begin{tabular}{ccc}
\hline Value & Frequency & Percentage \\
\hline $\begin{array}{c}\text { Family case } \\
\text { Parents' } \\
\text { consanguinity }\end{array}$ & 10 & 5.46 \\
\hline
\end{tabular}

Table 3. Frequencies of symptoms.

\begin{tabular}{ccc}
\hline Symptoms & Number & Percentage \\
\hline History of stroke & 2 & 1.09 \\
Loss of weight & 4 & 2.18 \\
Heart failure & 5 & 2.73 \\
Chest pain & 27 & 14.75 \\
Anasarca & 44 & 24.04 \\
Acute rheumatic fever (ARF) & 60 & 32.79 \\
Repeated angina & 90 & $49.18 \%$ \\
Orthopnea & 140 & 76.51 \\
\hline
\end{tabular}

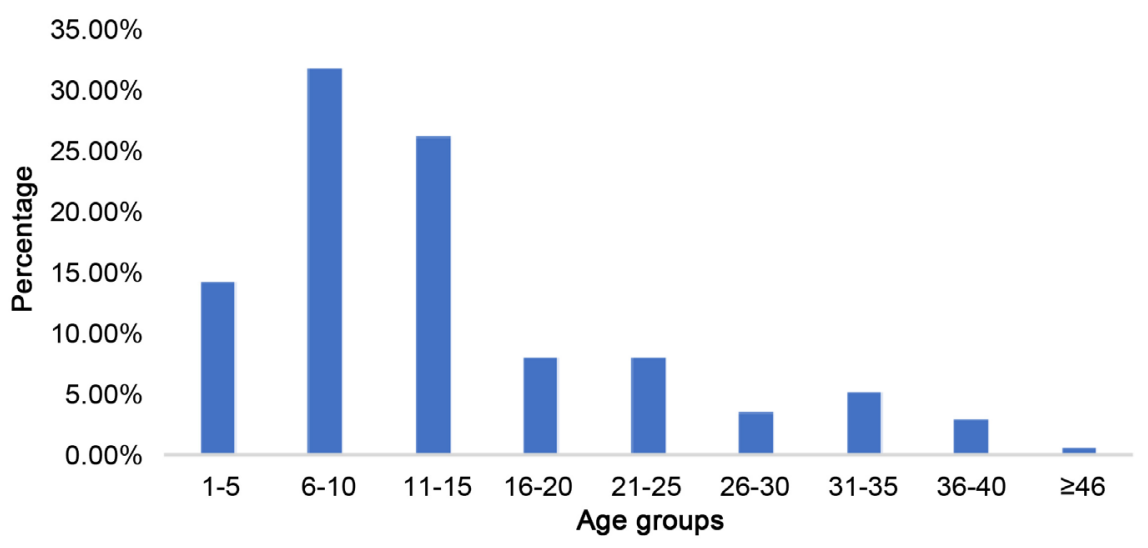

Figure 1. Age at diagnostic.

between 0 and 3 years with 45 patients from our study population who are concerned. Average time between year of symptoms and year of diagnosis was $13 \pm$ 19 years (Figure 2).

\subsection{Delays between Year of Diagnosis and Year of Surgery}

Patients are operated on most between 12 - 16 years after diagnosis. Average time between year of diagnosis and year of surgery was $10 \pm 14$ years (Figure 3 ).

\subsection{Clinical Diagnostics}

Based on the diagnosis, it seems that mitral valve is the most affected by rheumatic heart disease, most encountered pathologies in our series being mitral stricture (MR) with $22.5 \%$ of cases, mitral disease in $17.9 \%$ of cases and mitral regurgitation with $6.9 \%$. With regard to polyvalent diseases, combination of mitral 


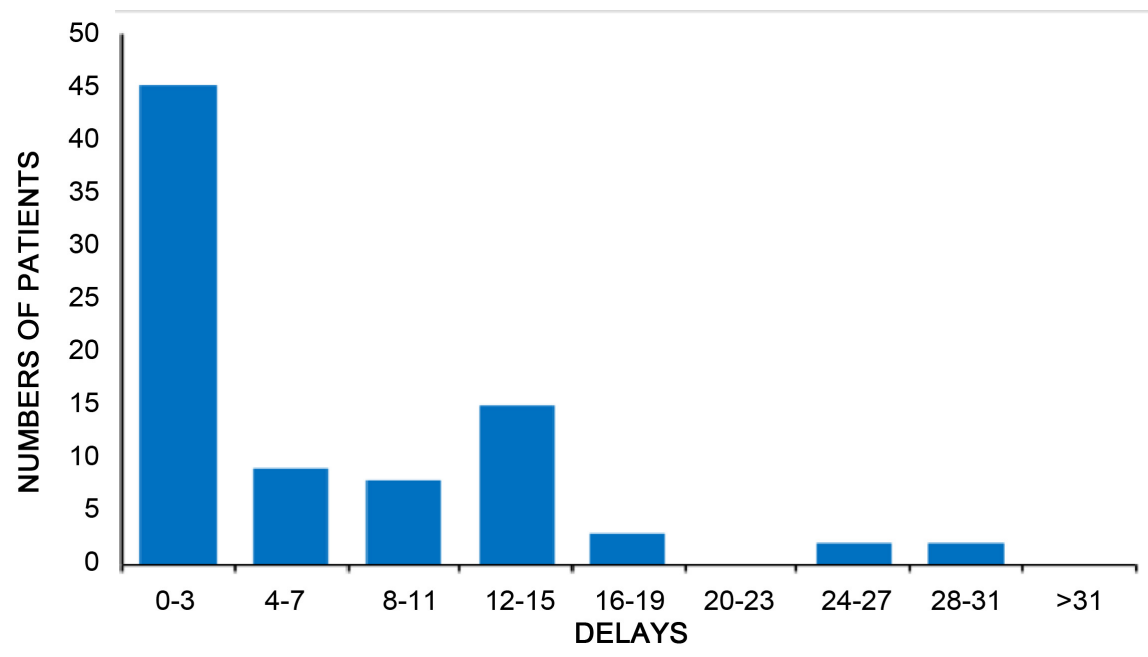

Figure 2. Delays between symptoms and diagnosis.

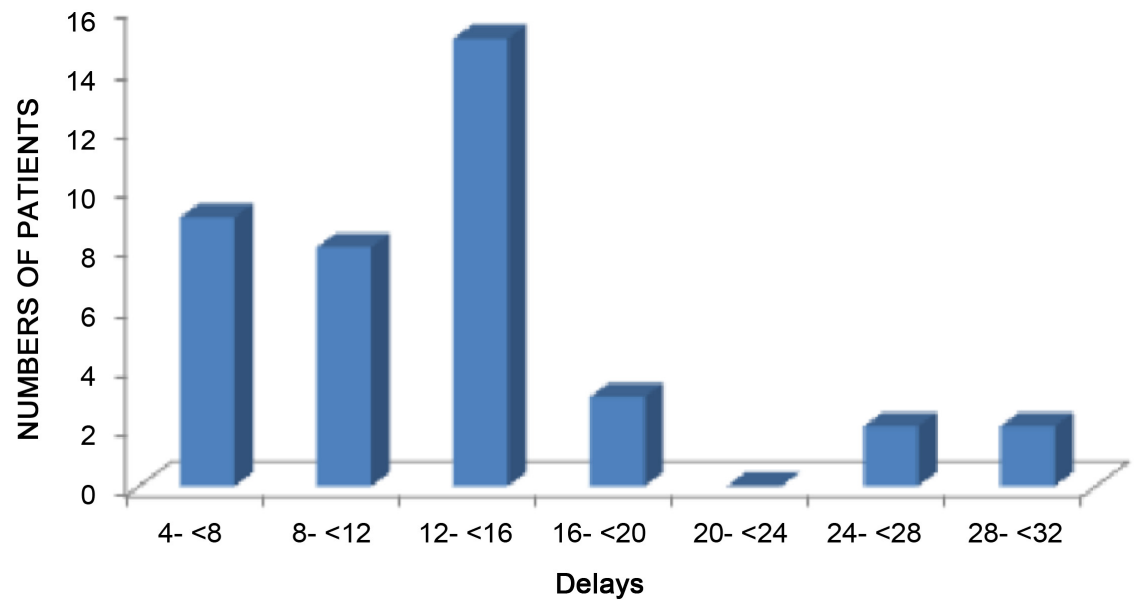

Figure 3. Delays between year of diagnosis and year of surgery.

disease and aortic disease is the most frequent in our patients with a percentage of $6.9 \%$ (Figure 4 ).

\subsection{Frequency of Surgical Procedures}

The most performed surgical intervention among the 133 patients operated on was mitral valve replacement with $31.87 \%$ of the patients concerned; $13.74 \%$ of patients had undergone both mitral valve replacement (MVR) and tricuspid valve repair (TP), 8.79\% aortic valve replacement (AVR), 10.99\% both MVR and AVR, 2.75\% had underwent intervention on their three valves (mitral, aortic and tricuspid). $27.45 \%$ of patients were awaiting surgery (Table 4 ).

\section{Discussion}

Surgery Clinic of Fann Hospital. Our study was interested in rheumatic heart valve disease strictly speaking from their natures and clinical manifestations to the possible surgical procedures which ensued. Certain socio-economic and 


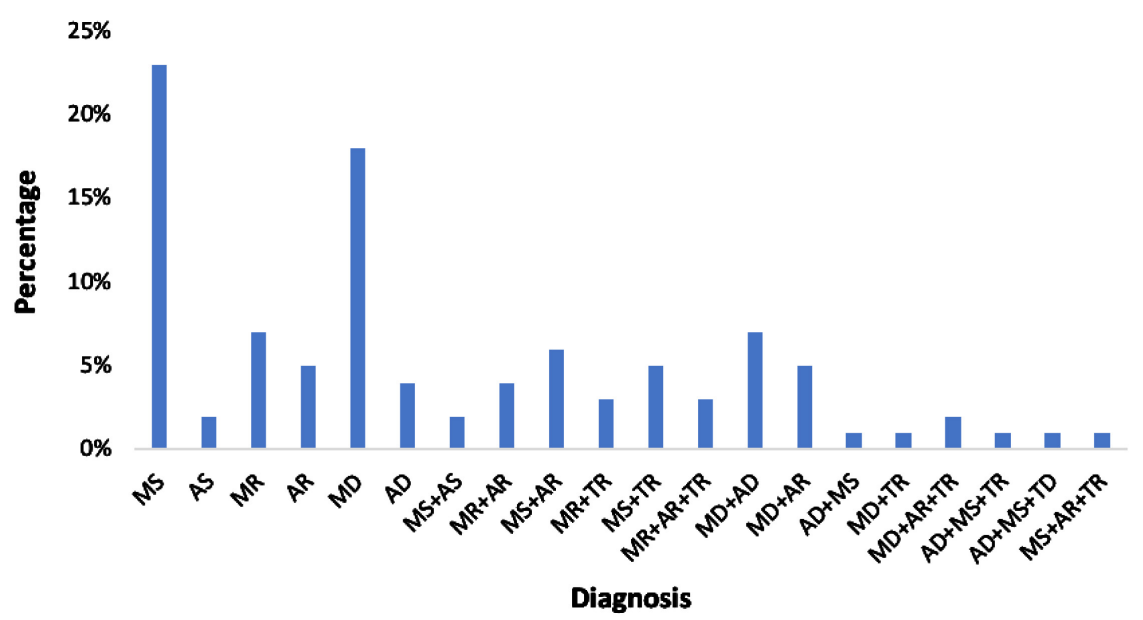

Figure 4. Patient clinical diagnosis.

Table 4. Distribution of surgical procedures.

\begin{tabular}{cc}
\hline Type of surgical proccedure & Percentage \\
\hline MVr & 1.1 \\
MVr + MVR & 1.1 \\
MC & 1.1 \\
MVr + AVR & 1.1 \\
A & 27.45 \\
MVR & 31.87 \\
AVR & 8.79 \\
MVR + AVR & 10.99 \\
MVR + TVr & 13.74 \\
MVR + AVR + TVr & 2.75
\end{tabular}

MVr: mitral valve repair; MVR: mitral valve replacement; MC: mitral commissurotomy; A: awaiting; AVR: aortic valve replacement; TVr: tricuspid valve repair.

clinical factors likely to play a role in the onset or course of RHVD were also assessed.

In our study, $5.46 \%$ of patients were family cases, which would indicate the existence of a genetic susceptibility to RHVD; results found in [7] and [8] go in the same direction. However, Cheadle has shown in [9] that this susceptibility is not as important as one might think since children with a family history of these pathologies did not present a significant increase in risk of developing RHVD; this situation could indicate an existence of a type of inheritance other than that of a single Mendelian gene [10].

RHVD occurs at a young age, but rarely before 3 years of age [11]. This is the case in our study where the average age of diagnosis was $14 \pm 9$ years.

There was an increase from $14.20 \%$ to $65.91 \%$ in the perception of clinical signs observed between 1 - 5-year and 6 - 20-year age groups, result which could be explained by the fact that the number of children with declared rheumatic 
heart disease would increase with age [12] [13]. Clinical signs most frequently perceived by patients are orthopnea, repeated angina and ARF with percentages of $76.51 \%, 49.18 \%$ and $39.79 \%$, respectively. These results corroborate those in [14] where $95 \%$ of orthopnea, $60 \%$ of repeated angina and $21 \%$ of ARF had been found. In [15] and [16] 100\% orthopnea had been found. In [17] [18] and [19] the most perceived symptom was ARF with respectively values of $65.9 \%, 65.8 \%$ and $82.3 \%$. Anasarca was the fourth most perceived sign with $24.04 \%$, and the third most perceived in [18] with a percentage of $23.7 \%$.

In [4], 7.5\% of all strokes occurring in least developed countries could be direct results of RHVD; a retrospective study in Ethiopia has shown that $26.5 \%$ of all stroke deaths are due to RHD. These results would confirm that RHVD would cause significant morbidity as a result of cardioembolic stroke and infectious endocarditis [20]. Our study reports a percentage of $1.9 \%$ stroke compared to $6.2 \%$ in [15].

Several researchers have attempted to explain delay in diagnosing ARF and RHVD; According to studies in [21], patients find themselves unable to cope with costs inherent in the detection and treatment of the disease because of physical incapacity in which disease placed them. In [22], there are often in certain regions no clinicians enough experienced to detect rheumatic fever early enough, their experience being limited to screening for rheumatic heart disease by detecting valve deterioration in elderly patients who developed an RAA in their youth. Conclusions made in [23] are that patients were referred to hospital centers often with much delay. The results of our study also made it possible to highlight this delay with an average age of diagnosis of $21 \pm 11$ years which is confirmed by the delay of $13 \pm 19$ years between onset of symptoms and diagnosis by clinician.

Time between diagnosis and intervention was long; the main reason could be the standard of living of patients when it is known that RHVD and its complications decrease quality of life due to the loss of income following poor attendance at work [20]. However, medical care for RHVD, from medical consultations and laboratory tests to medication, hospital admissions and finally surgical interventions is very expensive for patients and their families [21]. Another reason could be that some patients are not physically able to support the procedure, either because they are already weakened by the disease, or because they have become too old. In fact, valve replacement is cumbersome, expensive, and sometimes not feasible on site and presents certain risks.

Mitral stenosis $(22.5 \%)$ was much more frequent than mitral regurgitation (6.9\%), a situation which could be explained by the fact that early stages of RHD regress in $30 \%$ of cases, which regression is attributed to that of mitral regurgitation [24] [25] [26] [27]. On the other hand, in [18] [28], a diagnosis of mitral regurgitation had mainly been found with respectively $39.47 \%$ and $84 \%$. In our series, mitral disease was found in $17.9 \%$ of patients against $13.16 \%$ in [18]. It appears that mitral valve was the most affected, however no explanation has 
been found to date knowing that the four heart valves are born from the same tissue [29]. In contrast, in [30], mitral valve was affected at $44.06 \%$, and at $43.47 \%$ in those in [31]. Mitro-aortic pathology was the second most frequent with $22.91 \%$ followed by mitral stenosis (22.5\%); These results are different from those in [14] where a percentage of mitral and mitro-aortic pathologies of $79.41 \%$ and $10.29 \%$ respectively, a predominance of mitral stenosis of $19 \%$ had been found. In Alkhalifa (2008) series in [28], aortic regurgitation was the second most common diagnosis (40\%). In contrast, in [30], mitral disease predominated with $44.8 \%$, followed by mitral stenosis $(16.33 \%)$ and then mitral regurgitation (10.89\%).

In accordance with the predominance of mitral pathology, mitral valve replacement was the most performed intervention on patients with $31.28 \%$, a result which is significantly lower than that of $77 \%$ found in [14]. Mitral commissurotomy was performed more on the latter series 6\%) than on our series $(1.10 \%)$ and in [15] $(0.8 \%)$. In the latter, mitral valve repair was performed at $4.7 \%$ and an intervention on the three mitral, aortic and tricuspid valves at $91.5 \%$ whereas in our series, $1.10 \%$ of the interventions concerned the mitral plasty and only $2.75 \%$ a mitro-aorto-tricuspid intervention. In our study, $27.37 \%$ of patients were awaiting an intervention compared to $58 \%$ in [18] and $48.7 \%$ in [32]. Additional efforts should be made to facilitate access to surgical management for patients.

\section{Conclusions}

The presence of a significant number of family cases shows that there is a genetic susceptibility playing a role in the occurrence of the pathology. Orthopnea would be the most perceived clinical sign by patients, followed by repeated angina and ARF. A significant delay would elapse between the diagnosis and the surgical intervention. Mitral valve would be most affected by the pathology, which would affect frequency of surgical procedures on this valve. Our study has a limit: it is monocentric. Although our sample is consistent, it is not fully representative of Senegalese population. Indeed, even if Fann Hospital's Thoracic and Cardiovascular Surgery Clinic is the only cardiac surgery center in Dakar and even in Senegal, a significant number of patients with RHVD are followed in other health facilities through the country. As a result, there is in our sample an underrepresentation of certain ethnic groups, certain areas of residence and certain forms of pathology.

Considerable efforts should be made to raise awareness about the signs of the disease, and in favor of prevention based on the most determining factors. Indeed, even if there is no pathognomonic sign of this disease and the diagnosis is sometimes difficult, clinical and paraclinical diagnostic tools generally make it possible to recognize it. Thus, in view of the results, considerable efforts are to be made in order to carry out the following actions:

Establish a control strategy that integrates the medical component and the 
social component.

$>$ Include health education and patient education in the action plan by promoting communication of ideas, but also listening and feedback.

Consider patient demand and not just try to respond

$>$ Identified medical needs.

It therefore becomes more than urgent to organize free screening sessions, awareness programs on the disease in relation to its causes, its management and its consequences.

\section{Conflicts of Interest}

The authors declare no conflicts of interest regarding the publication of this paper.

\section{References}

[1] Seck, E.M., Fall, M., Bao, O., Hane, L., Sarr, M., Kane, A., Diop, B., Diouf, S.M. and Ba, S.A. (1992) Cardiopathies rhumatismales au Sénégal: Aspects cliniques et medico-sociaux. Cardiologie Tropicale, 18, 140.

[2] Okello, E., Beaton, A., Mondo, C.K., Kruszka, P., Kiwanuka, N., Odoi-Adome, R., et al. (2014) Rheumatic Heart Disease in Uganda: The Association between MHC Class II HLA DR Alleles and Disease: A Case Control Study. BMC Cardiovascular Disorders, 14, 28. https://doi.org/10.1186/1471-2261-14-28

[3] Carapetis, J.R., McDonald, M. and Qilson, N.J. (2005) Acute Rheumatic Fever. The Lancet, 366, 155-168. https://doi.org/10.1016/S0140-6736(05)66874-2

[4] Carapetis, J.R., Steer, A.C., Mulholland and Weber, M. (2005) The Global Burden of Group A Streptococcal Diseases. The Lancet Infectious Diseases, 5, 685-694. https://doi.org/10.1016/S1473-3099(05)70267-X

[5] Mocumbi, A.O. (2015) Rheumatic Heart Disease in Africa: Is There a Role for Genetic Studies? Cardiovascular Journal of Africa, 26, S21-S26. https://doi.org/10.5830/CVJA-2015-037

[6] Scott, D.W. (2009) Sturges' Rule. WIRES Computational Statistics, 1, 303-306. https://doi.org/10.1002/wics.35

[7] Taranta, A., Torosdag, S., Metrakos, J.D., Jegier, W. and Uchida, I. (1959) Rheumatic Fever in Monozygotic and Dizygotic Twins. Circulation, 20, 778.

[8] Denbow, C.E., Barton, E.N. and Smikle, M.F. (1999) The Prophylaxis of Acute Rheumatic Fever in a Pair of Monozygotic Twins: The Public Health Implications. West Indian Medical Journal, 48, 242-243.

[9] Cheadle, W. (1889) Harveian Lectures on the Various Manifestations of the Rheumatic State as Exemplified in Childhood and Early Life. The Lancet, 60, 821-827. https://doi.org/10.1016/S0140-6736(01)90541-0

[10] Bryant, P.A., Robins-Browne, R., Carapetis, J.R. and Curtis, N. (2009) Some of the People, Some of the Time: Susceptibility to Acute Rheumatic Fever. Circulation, 119, 742-753. https://doi.org/10.1161/CIRCULATIONAHA.108.792135

[11] Kimbally-Kaky, G., Makoumbou and Nzingoula, S. (2002) Acute Rheumatic Fever among Children in the Republic of Congo: Report of 56 Cases. Dakar Medical, 47, 57-59.

[12] Rizvi, S.F., Khan, M.A., Kundi, A., Marsh, D.R., Samad, A. and Pasha, O. (2004) 
Status of Rheumatic Heart Disease in Rural Pakistan. Heart, 90, 394-399. https://doi.org/10.1136/hrt.2003.025981

[13] Kane, A., Mirabel, M., Toure, K., Perier, M.C., Fazaa, S., Tafflet, M., et al. (2013) Echocardiographic Screening for Rheumatic Heart Disease: Age Matters. International Journal of Cardiology, 168, 888-891. https://doi.org/10.1016/j.ijcard.2012.10.090

[14] Faissal, M.Z. (2011) La sténose mitrale rhumatismale isolée (A propos de 129 cas). Thèse $N^{\circ} 022 / 11$, Faculté de Médecine et de Pharmacie, Université Sidi Mohamed Ben Abdellah, Fès, 86 p.

[15] Berriane Maria (2009) Traitement chirurgical des triples valvulopathies: Expérience du service de Chirurgie cardiovasculaire $B$. Thèse $\mathrm{N}^{\circ} 112$ pour l'obtention d'un diplôme de Docteur en Médecine.

[16] Ciss, A.G, Dieng, P.A., Ba, P.S., Gaye, M., Diatta, S., Fall, M.L., et al. (2012) Surgical Results for Rheumatic Heart Valve Disease in Senegal. Ann. Afr. Chir. Thor. Cardiovasc, 7, 19.

[17] Thakur, J.S., Negi, P.C., Ahluwalia, S.K. and Vaidya, N.K. (1996) Epidemiological Survey of Rheumatic Heart Disease among School Children in the Shimla Hills of Northern India: Prevalence and Risk Factors. Journal of Epidemiology and Community Health, 50, 62-67. https://doi.org/10.1136/jech.50.1.62

[18] Goeh Akue, E., Gbeasor, F.D., Baragou, S., Damorou, F., Gbadoe, A.D., Kessiek, K., et al. (2008) Les cardiopathies rhumatismales au Centre Hospitalier Universitaire Tokoin de Lomé. Rev. CAMES - Série A, 6, 12-17.

[19] Diao, M., Kane, A., Doumbia, A.S., Leye, M.M.C.B.O., Mbaye, A., Kane, A., Diop, I.B., et al. (2005) Cardiopathies rhumatismales évolutives à propos de 17 cas colligés au CHU de Dakar. Med Trop, 65, 339-342.

[20] Karthikeyan, G., Zùhlke, L., Engel, M., Rangarajan, S., Yusuf, S., Teo, K., et al. (2012) Rationale and Design of a Global Rheumatic Heart Disease Regitry: The Remedy Study. American Heart Journal, 163, 535-540.

https://doi.org/10.1016/j.ahj.2012.01.003

[21] Robertson, K.A. and Mayosi, B.M. (2008) Rheumatic Heart Disease: Social and Economic Dimensions. South African Medical Journal, 98, 780-781.

[22] Carapetis, J.R. (2007) Rheumatic Heart Disease in Developing Countries. The New England Journal of Medicine, 357, 439-441. https://doi.org/10.1056/NEJMp078039

[23] Ngaidé, A.A., Mbaye, A., Kane, A., Ndiaye, M.B., Jobe, M., Bodian, M., et al. (2015) Prevalence of Rheumatic Heart Disease in Sengalese School Children: A Clinical and Echocardiographic Screening. Heart Asia, 7, 40-45.

https://doi.org/10.1136/heartasia-2015-010664

[24] Paar, J.A., Berrios, N.M., Rose, J.D., Caceres, M., Pena, R., Perez, W., et al. (2010) Prevalence of Rheumatic Heart Disease in Children and Young Adults in Nicaragua. The American Journal of Cardiology, 105, 1809-1814.

https://doi.org/10.1016/j.amjcard.2010.01.364

[25] Saxena, A., Ramakrishnan, S., Roy, A., Seth, S., Krishnan, A., Misra, P., et al. (2011) Prevalence and Outcome of Subclinical Rheumatic Heart Disease in India: The RHEUMATIC (Rheumatic Heart Echo Utilisation and Monitoring Actuarial Trends in Indian Children). Study Heart, 97, 2018-2022.

https://doi.org/10.1136/heartjnl-2011-300792

[26] Bhaya, M., Beniwal, R., Panwar, S. and Panwar, R.B. (2011) Two Years of Follow-Up Validates the Echocardiographic Criteria for the Diagnosis and Screening of Rheumatic Heart Disease in Asymptomatic Populations. Echocardiography, 28, 
929-933. https://doi.org/10.1111/j.1540-8175.2011.01487.x

[27] Beaton, A., Okello, E., Aliku, T., Lubega, S., Lwabi, P., Mondo, C., et al. (2014) Latent Rheumatic Heart Disease: Outcomes 2 Years after Echocardiographic Detection. Pediatric Cardiology, 35, 1259-1267.

https://doi.org/10.1007/s00246-014-0925-3

[28] Alkhalifa, M.S., Ibrahim, S.A. and Osman, S.H. (2008) Pattern and Severity of Rheumatic Valvular Lesions in Children in Khartoum, Sudan. Eastern Mediterranean Health Journal, 14, 1015-1021.

[29] Seckeler, M.D. and Hoke, T.R. (2011) The Worldwide Epidemiology of Acute Rheumatic Fever and Rheumatic Heart Disease. Clinical Epidemiology, 3, 67. https://doi.org/10.2147/CLEP.S12977

[30] Toure, S., Balde, M.D., Conde, A., Toure, B.M. and Fofana, M. (1998) Aspects épidémiologiques, Cliniques et évolutifs de 89 cas de maladie mitrale rhumatismale. Médecine d'Afrique Noire, 45, 11.

[31] Fofana, M., Toure, S., Guilavogui, K.M. and Balde, O.D. (1984) Épidémiologie des valvulopathies rhumatismales à Conakry. GUI Médicale, 2, 7-9.

[32] Coulibaly, A. (2005) Les cardiopathies juvéniles au service de cardiologie de l'hôpital Gabriel Touré et de l'hôpital Mère Enfant Le Luxembourg a propos de 226 cas. Thèse médecine $\mathrm{N}^{\circ} 141$, Bamako. 